\title{
MODEL ELABORATION LIKELIHOOD DALAM PEMBENTUKAN PERSONAL BRANDING PITA'S LIFE DI YOUTUBE CHANNEL
}

\author{
Maria Fatima Kue, Christiana Sahertian \\ Program Studi Ilmu Komunikasi, Fakultas Ilmu \\ Sosial dan Ilmu Politik Universitas Merdeka \\ Malang \\ mariafatimakue@gmail.com
}

\begin{abstract}
Abstrack
This study aims to describe the formation of the personal pranding Pita 's Life vlog on youtube through the analysis of Model Elaboration Likelihood. From this research, it is expected to provide input and advice to the Youtuber to better display content that is better and not detrimental to themselves and others, so as to produce a positive outlook on their personal. The type of research used in this research is qualitative descriptive using the content analysis design. The use of the content analysis method was carried out in this study because the source of the data produced was verbal communication from the vlog of the Ribbon which was then reidentified in writing. The population used in this study was 64 'Pita's Life vlog shows from July to November 2018. The sample used in this study was the Pita Vlog show which only aired a life of 20 husbands and children. This research proves that the formation of the Pita's Life vlog personal branding on Youtube can be analyzed using the Model Elabation Likelihood. This is because both the central line and peripheral lines in the Elaboration Likelihood Model are both processes in forming the Ribbon personal branding. In the central path, it shows that the arguments uttered by the Pita contain positive things. The argument expressed by Pita is also supported by its quality as a source of messages that appears to have ethos, attractions and power on peripheral lines, so both the argumentation and quality of the Ribbon as a communicator make Pita's vlog show an interesting show to be watched by the public.
\end{abstract}

Keyword : Elaboration Likelihood Model, Personal Branding, Youtube Channel

\section{Abstrak}

Penelitian ini bertujuan mendeskripsikan mengenai pembentukan personal pranding Pita's Life vlog di youtube melalui analisis Model Elaboration Likelihood. Rekomendasi yang dihasilkan memberikan masukan, saran dalam menyusun konten, sehingga menghasilkan pandangan yang positif terhadap personal dirinya. Jenis penelitian yang digunakan dalam penelitian ini adalah deskriptif kualitatif dengan menggunakan rancangan analisis isi. Penggunaan metode analisis isi dilakukan dalam penelitian ini karena sumber data yang dihasilkan adalah komunikasi verbal dari vlog Pita yang kemudian diidentifikasi kembali secara tertulis dari tayangan Pita's Life vlog berjumlah 64 dari bulan Juli-November 2018. Sampel adalah tayangan vlog Pita yang hanya menayangkan kehidupannya keluarga sebanyak 20 vlog. Penelitian ini membuktikan bahwa pembentukan personal branding Pita's Life vlog di Youtube dapat dianalisis dengan menggunakan Model Elabation Likelihood. Hal tersebut dikarenakan, baik jalur sentral maupun jalur periferal pada Model Elaboration Likelihood ini samasama merupakan proses dalam pembentukan personal branding Pita. Pada jalur sentral, menunjukan bahwa argumentasi yang diucapkan oleh Pita berisi hal-hal yang positif. Argumentasi yang diucapkan Pita tersebut juga didukung oleh kualitasnya sebagai sumber pesan yang terlihat memiliki ethos, atraksi dan kekuatan pada jalur periferal, sehingga baik argumentasi maupun kualitas Pita sebagai komunikator menjadikan 
tayangan vlog Pita sebagai sebuah tayangan yang menarik untuk ditonton oleh kalangan masyarakat.

\section{Kata Kunci : Model Elaboration Likelihood, Personal Branding, Youtube Channel}

\section{PENDAHULUAN}

Model Elaboration Likelihood
atau dikenal dengan istilah ELM
merupakan salah satu teori komunikasi
yang menjelaskan mengenai bagaimana
strategi komunikator dikomunikasikan
terutama dalam konteks berkomunikasi
merek. Kualitas komunikor dan pesan yang
berkualitas tersebut akan menggiring pada
pembentukan sikap komunikan yang
dikehendaki baik secara kognitif, afektif,
maupun konotatif (Griffin,2010:206). Asumsi yang mendasari teori ini adalah bahwa orang dapat menilai sebuah pesan secara mendalam, penuh kehati- hatian dan dengan pemikiran yang kritis, namun pada suatu kondisi yang lain, orang juga dapat menilai pesan sambil lalu saja tanpa mempertimbangkan argumentasi apa yang mendasari pesan tersebut. Artinya, adanya kemungkinan untuk memahami pesan persuasif secara mendalam tergantung pada cara seseorang memproses pesan tersebut. Berbicara mengenai Model Elaboration Likelihood apalagi dalam konteks merek, tentunya tidak terlepas dari yang namanya Personal Branding. Hal tersebut dikarenakan Personal Branding dapat memperkuat pesan yang disampaikan, sehingga proses persuasi dapat berjalan dan pembentukan sikap terjadi.

Menurut Boarnet \& Crane (2013), Personal branding merupakan faktor yang telah ada dan terbentuk disetiap diri masyarakat atau individu berbeda-beda, tergantung dari lingkungan sekitarnya. Dengan kata lain, personal branding berarti bagaimana persepsi orang lain mengenai kepribadian, kemampuan, serta prestasi yang ada dalam diri seseorang. Personal branding juga dapat dikatakan sebagai citra diri. Selain itu, Personal Branding seringkali juga dikaitkan dengan kualitas kemampuan dan kapabilitas seseorang. Dalam arus perkembangan teknologi informasi dan media komunikasi saat ini, semakin banyak persaingan antar individu Personal branding lebih banyak dilakukan dalam dunia virtual. Oleh sebab itu, tidak dapat dipungkiri lagi bahwa pemanfaatan media massa, khususnya media baru saat ini sangat banyak digunakan sebagai sarana utama untuk mengekpresikan diri.

Youtube merupakan salah satu bentuk media baru, dan merupakan salah satu media sharing atau berbagi video paling populer, memiliki beragam viewers yang setiap hari memenuhi kebutuhan untuk mendapatkan informasi dari situs ini. Umumnya, video- video di Youtube berupa klip musik, film, serta video buatan para penggunanya sendiri. Dahulu, orang memiliki kebiasaan untuk menceritakan kebiasaan baik atau buruknya hanya melalui buku diary yang disimpan dan dibaca sendiri. Setelah muncul istilah Blog dalam Youtube, orang bisa menulis pengalaman ataupun sesuatu yang di suka dan tidak suka yang dituangkan ke dalam sebuah karya tulisan dan dibaca banyak orang. Seiring berkembangnya teknologi saat ini, muncul istilah baru dalam Youtube, yaitu Video Blog (Vlog), dimana orang tidak hanya bisa mengasilkan tulisan, namun dapat menggunakan video yang di share ke Youtube Channel untuk bisa ditonton banyak orang.

Kehadiran media baru dalam hal 
ini Video Blog, dimanfaatkan sebagai media komunikasi oleh semua orang dengan masyarakat lainnya. Dapat dikatakan juga bahwa Video Blog telah menjadi ruang untuk mengkomunikasikan diri, menampilkan diri, mencari perhatian, bahkan promosi diri kepada masyarakat luas. Namun, yang perlu disadari adalah pemanfaatan media baru seperti Vlog tersebut membuka peluang besar bagi masyarakat lainnya untuk merespon dan menilai diri seseorang. Apabila yang ditampilkan berkenan dan dapat diterima oleh masyarakat, maka dapat membentuk personal branding seseorang dengan baik. Sebaliknya jika yang ditampilkan adalah kurang berkenan dan tidak dapat diterima, maka akan membentuk personal branding yang kurang baik juga.

Tidak sedikit orang Indonesia yang mengambil bagian dalam hal tersebut. Bahkan orang Indonesia yang pindah ke luar negeri, baik karena adanya perkawinan maupun pekerjaan, saat ini sangat banyak berlomba- lomba untuk membagikan pengalamannya selama berada di luar negeri melalui Video Blog. salah satunya adalah Pita"s Life. Pita"s Life merupakan sebuah akun $v \log$ milik seorang Youtuber bernama Novita Henderson atau yang sering dikenal dengan sebutan Pita. Pita sendiri berasal dari Maluku, memiliki suami seorang USA Airforce, dan saat ini tinggal di Amerika Serikat. Ibu dua anak ini, selalu mengupdate kegiatan sehariharinya. Menjadi seorang istri Air Force dan tinggal di Amerika Serikat, tidak membuat Pita untuk berhenti menunjukkan dirinya yang sederhana dalam Vlognya. Budaya Timur tempat Pita berasal selalu ditunjukkan nya, seperti makan menggunakan tangan, berteriak, berbicara dengan nada suara besar, bahkan dialek Maluku yang yang masih sangat kental, digunakan sebagai bahasa sehari-harinya di Vlog. Namun, hal tersebut tetap terlihat menarik dan Pita tetap disukai oleh para penontonnya. Hal tersebut terbukti dengan banyak nya subscriber yang mencapai 432 ribu dan penonton vlog hingga ratusan ribu penonton.

Untuk menjadi seorang Vlogger dengan jumlah penonton yang cukup banyak tersebut, personal branding merupakan suatu hal yang penting, terlebih bagi seorang Pita. Dalam hal ini, tentunya banyak hal yang telah Pita lakukan agar pandangan para penonton mengenai dirinya selalu positif. Oleh sebab itu, Model Elaboration Likelihood dipilih sebagai teori untuk mengkaji bagaimana proses pengolahan pesan yang dilakukan oleh komunikan sehingga kemungkinan pembentukan personal branding Pita's Life vlog melalui media Youtube tersebut.

\section{New Media (Media Baru)}

"Media baru" adalah berbagai perangkat teknologi komunikasi yang terbagi ciri yang sama yang mana selain baru, dimungkinkan dengan digitalisasi dan ketersediannya yang luas untuk penggunaan pribadi sebagai alat komunikasi (McQuail, 2011:148). Media baru muncul akibat inovasi teknologi dalam bidang media seperti internet, teknologi fiber optic, dan komputer. Oleh sebab itu, secara interaktif, pengguna dapat membuat pilihan respon produk secara beragam. McQuail (2011:156-157) mengelompokkan media baru berdasarkan jenis penggunaan, konten, dan konteks seperti berikut : media komunikasi antarpribadi (interpesonal communication media), media permainan interaktif interactive play media), media pencarian informasi (information search media), media partisipasi kolektif (collective 
participatory media), substiutsi media penyiaran (substitution of broadcasting media).

Munculnya media baru tidak menyebabkan media konvensional hilang, melainkan keduanya terus berevolusi dan beradaptasi. Baik media baru maupun konvensional tetap bersaing untuk mendapatkan perhatian masyarakat serta memberikan kontribusi bagi pengembangan mediamedia lainnya yang belum ditemukan. Munculnya media baru tidak menyebabkan media konvensional hilang, melainkan keduanya terus berevolusi dan beradaptasi. Baik media baru maupun konvensional tetap bersaing untuk mendapatkan perhatian masyarakat serta memberikan kontribusi bagi pengembangan mediamedia lainnya yang belum ditemukan (Biagi, 2010:238-239).

\section{Media Sosial}

Media sosial adalah medium di internet yang memungkinkan pengguna merepresentasikan dirinya meupun berinteraksi, bekerja sama, berbagi, berkomunikasi dengan pengguna lain, dan membentuk ikatan sosial secara virtual (Nasrullah, 20017:11).

Komunitas-komunitas pecinta youtube menganggap realitas sesungguhnya adalah realitas virtual. Sehingga suatu perusahaan dapat menggunakan taknik pemasaran yang serupa misalnya menggunakan uang sebagai alat untuk menjalankan aplikasi ini agar dapat bertahan hidup (Nurudin, 2012: 54-89). Munculnya media sosial memberikan arah baru terhadap pendefisian ulang hubungan khalayakmedia, Holmes (Narullah, 2017: 95).

\section{Youtube dan Vlogger dan Personal Branding}

Menurut FAMOUS ID dalam Pradipta (2017:13), ada beberapa konten vlog yang ada di Indonesia, yaitu : Daily Vlog, yaitu jenis vlog yang diproduksi oleh para Vlogger hampir setiap hari. Travel vlog, vlogger menayangkan perjalan ke tempattempat yang mereka kunjungi. Food Vlog, yaitu video yang mencakup mengenai beberapa jenis konten seperti review makanan, review tempat makan, wisata kuliner, ataupun tutorial masak. Melalui video jenis ini, penonton bisa memperoleh informasi tentang kekayaan kuliner baik yang ada di dalam negeri maupun di luar negeri. Relationship Vlog, adalah video yang membagi pengalaman dan tips menjalani hubungan. Konten relationship vlog ini merupakan konten yang paling digemari oleh para remaja. Beauty \& Lifestyle Vlog, adalah video yang didominasi oleh vlogger berjenis kelamin wanita. Kids Vlog, yaitu jenis vlog yang paling digemari oleh penonton Youtube Indonesia. Dalam video ini menayangkan tingkah laku yang menggemaskan dari para balita.

Menurut Kertajaya (2000:184), brand sebagai value indicator, yaitu indikator yang menggambarkan seberapa kokoh atau solidnya value yang ditawarkan ke pelanggan, karena merek menggambarkan nilai yang ditawarkan kepada orang lain, sehingga menjadi alat kunci bagi pelanggan untuk menentukan pilihan pembelian.

Personal branding dengan kata lain adalah membentuk persepsi 
masyarakat terhadap aspek yang dimiliki seseorang, diantaranya adalah kepribadian, kemampuan, atau nilainilai dan bagiamana semua itu menimbulkan persepsi positif dari masyarakat yang pada akhirnya dapat digunakan sebagai alat pemasaran. Personal brand merupakan persepsi yang tertanam dan terpelihara dalam benak orang lain, tujuannya adalah agar orang lain memiliki pandangan positif atau persepsi positif sehingga bisa berlanjut ke trust (kepercayaan). Hal tersebut disebabkan kepercayaan merupakan penentuan suatu komunikasi yang efektive.

Untuk mencapai sebuah personal brand yang kuat terdapat tiga hal yang mendasar yang ditulis oleh McNally \& Speak (2004), yaitu : Kekhasan, Relevansi, Konsistensi.

Aristoteles dalam buku Psikologi Komunikasi menyebutkan karakter seorang efektivitas komunikator sebagai ethos yang merupakan kredibilitas, dimana selain memiliki Expertise (keahlian), seorang komunikator juga perlu adanya Trustworthiness (dapat dipercaya) Hovlan dan Weiis (Rakhmat, 2005:256). Selain itu, faktor-faktor lainnya yang mempengaruhi efektivitas komuninator adalah atraksi komunikator (source attractiveness) dan kekuasaan (source power).

\section{Model Elaboration Likelihood}

Model Elaboration Likelihood atau model kemungkinan elaborasi merupakan sebuah teori mengenai persuasi, karena memperkirakan kapan dan bagaimana seseorang akan dapat atau tidak dapat mengubah pendapatnya (dibujuk) oleh adanya suatu pesan atau argumen yang diterimanya, Morisan (2014:83). Menurut teori ini, cara orang memproses suatu informasi pesan terdiri dari dua cara yaitu melalui jalur pusat (central route) atau melalui jalur perferal (peripheral route). Kedua jalur tersebut berada didalam otak manusia. Elaborasi atau pemikiran kritis terjadi pada jalur central sedangkan pemikiran yang kurang kritis terjadi pada jalur peripheral.



(Gambar 2.1 : Model Elaboration Likelihod Model // Griffin, 2003:199

Petty dan Cacciopo, menjelaskan mengenai perubahan sikap baik secara kognitif, afektif, maupun konotatif menggunakan dua rute, yaitu rute sentral dan rute periferal. Jalur sentral (Central Route)dan jalur periferal Kredibilitas menjadi petunjuk orang untuk mempercayai perkataannya. (Widiastuti, 2017:593)

\section{METODE PENELITIAN}

Jenis penelitian yang digunakan adalah deskripstif kualitatif dengan menggunakan metode analisis isi. Analisis isi merupakan konteks yang 
sensitif, oleh karena itu memungkinkan peneliti untuk memproses teks data yang signifikan, bermakna, informatif dan presentasional kepada orang lain (Krippendorf, 2006:41).

Populasi penelitian ini adalah tayangan Pita's Life vlog yang berjumlah sebanyak 64 dari bulan JuliNovember 2018. Sampel adalah bagian dari jumlah dan karakteristik yang dimiliki oleh populasi tersebut. Sampel yang diambil dalam penelitian ini adalah tayangan Pita ${ }^{\text {ee }}$ L Life $v$ log dari bulan JuliNovember 2018 yang berjumlah 20 video, dengan menggunakan teknik purposive sampling, yaitu metode menentukan sampel yang dilakukan dengan pertimbangan atau kriteria tertentu.

Teknik analisis data yang digunakan adalah melakukan analisis pada jalur sentral dan jalur periferal. Pada jalur sentral personal branding Pita's Life vlog akan dianalisis berdasarkan tipe argument yang sudah dikategorisasi yaitu strong argument, neutral argument, dan weak argument dengan menggunakan analisis isi. Pada jalur periferal, personal branding Pita's Life akan dianalisis berdasarkan psikologi komunikator yaitu melalui Ethos, Attactiveness (Atraksi), dan kekuasaan.

\section{HASIL PENELITIAN DAN PEMBAHASAN}

Pita's Life Vlog merupakan sebuah akun vlog milik salah satu Youtubers yang bernama Nofita Henderson atau yang dikenal dengan nama Pita. Karir Pita menjadi seorang Youtubers dimulai sejak tahun 2016 dimana Pita mengupload video-video pendek (vlog) bersama suami dan anaknya. Di dalam vlog tersebut diceritakan mengenai segala kegiatan keseharian yang mereka lakukan, hingga vlog proses persalinan anak keduanya Rachel. Hingga saat ini vlog yang dihasilkan sudah mencapai hingga 488 video, yang didalamnya berisi berbagai jenis konten mulai dari beauty vlog, travelvlog, mukbang vlog, family vlog dengan jumlah subscriber yang cukup banyak yaitu 493 ribu.

Tidak hanya cantik, namun didalam vlognya Pita juga menunjukkan ciri khas logat Maluku yang digunakannya dalam berkomunikasi, serta gayanya yang sederhana dan tidak jaim. Penampilan apa adanya yang ditunjukkannya melalu vlognya inilah yang membuat banyak penonton menikmati bahkan terhibur, mulai dari kalangan anak muda hingga orang dewasa.

\section{Analisis Data}

Jalur sentral adalah jalur yang digunakan ketika seseorang mengelaborasi pesan secara kognitif sehingga hasil dari elaborasi pesan secara kognitif tersebut dapat membentuk personal branding. Artinya, melalui jalur ini sosok seseorang akan dinilai dari apa yang dikatakan ataupun perilaku yang dilakukan secara personal atau secara keterlibatan dengan orang lain.

Tabel 1. Hasil Jumlah Tipe Argumen

\begin{tabular}{|l|l|l|}
\hline No. & Tipe Argumen & Jumlah Kalimat \\
\hline 1. & $\begin{array}{l}\text { Strong } \\
\text { Argumen }\end{array}$ & $142(80,22 \%)$ \\
\hline 2. & $\begin{array}{l}\text { Neutral } \\
\text { Argument }\end{array}$ & $12(6,77 \%)$ \\
\hline
\end{tabular}


JURNAL NOMOSLECA

Volume 5 Nomor 1, April 2019

\begin{tabular}{|l|l|l|}
\hline 3. & $\begin{array}{l}\text { Weak } \\
\text { Argument }\end{array}$ & $23(12,99 \%)$ \\
\hline & Frekuensi & $177(100 \%)$ \\
\hline
\end{tabular}

Berdasarkan vlog yang telah diidentifikasi, melalui jalur sentral secara kognitif, peneliti melihat bahwa kegiatan yang ditunjukan Pita dalam vlognya tidak hanya menceritakan kehidupan pribadinya, tetapi Pita juga melibatkan kehidupannya bersama orang lain yaitu suami dan kedua anakanaknya yang diwakili oleh argumentasi-

argumentasi

yang disampaikan Pita dalam vlognya. Peneliti melihat keterlibatan yang ditunjukan Pita melalui vlog ketika bersama kedua anaknya Rachel dan Zach menunjukkan Pita sebagai sosok ibu yang peduli terhadap kedua anaknya. Hal tersebut diwakili oleh beberapa argumentasi yang telah diidentifkasi oleh peneliti dalam penyajian data, yaitu :

1. "Rachel I promise you, if there's any competition, Im gonna take you with Zach, You and Zach always."

2. "No, dont hit Rachel, Zachy. Dont hit her. Just tell her, Rachel not good. Dont throw the elastic hair tale"

3. "Rachel, sharing with your brother please. Dont be stingy."

4. "Take this chair put back right there, both of you from here, Very good Zach, be carefull."

Berdasarkan beberapa argumentasi yang mewakili tersebut, peneliti melihat bahwa selain menjadi seorang Youtuber yang aktif dalam membuat $v$ log, hal tersebut justru tidak membuat Pita melupakan tanggung jawabnya sebagai seorang Ibu.
Walaupun Pita sibuk bekerja memegang kamera dan merekam dirinya yang sedang bercerita atau sedang memasak, dan melakukan kegiatan lainnya kemudian anaknya tiba-tiba menangis ataupun berkelahi dan rewel, Pita selalu menyempatkan waktu untuk menjeda pekerjaannya dan menyempatkan waktu bersama kedua anaknya seperti dengan memberikan nasihat atau teguran halus yang membangun kepada Zach dan Rachel.

Selain menjadi sosok Ibu yang peduli terhadap kedua anaknya, peneliti juga melihat bahwa Pita merupakan seorang sosok wanita yang penyayang. Hal tersebut diwakili oleh beberapa argument yang telah diidentifikasi oleh peneliti dalam penyajian data yaitu :

1. "Everysingle time kalau saya melihat binatang yang mati di jalan yang sudah ditabrak dan tambah ditabrak lagi, I feel really- really bad."

2. "Saya dan suami selama kami hidup, shadow, willow, zhowy, ronan, hunter dan stella akan dinafkahi dengan baik. Segalasesuatu yang mereka perlukan seperti pengobatan, toys, dll, we gonna work for it, we know ketika kita memutuskan untuk mengambil mereka, we have to responbility."

3. "You know whats the best things that I get from You?? When I hug you."

4. "Love you too"

Berdasarkan argumentasi yang diucapkan Pita dalam vlog tersebut, peneliti melihat bahwa Pita selalu mengucapkan kalimat romantis yang tidak hanya diberikan kepada Suaminya tetapi juga kepada Rachel dan Zach. Namun, perasaan sayang tersebut tidak 
hanya diberikan kepada keluarganya tetapi juga kepada binatang. Hal tersebut terlihat dari argumentasinya yang menunjukkan bagaimana Pita selalu memperhatikan kebutuhankebutuhan binatang peliharannya.

Selanjutnya, peneliti juga melihat Pita sebagai sosok yang tidak meninggalkan ciri khas daerah asalnya. Hal tersebut diwakilkan oleh argumentasi dalam penyajian data yaitu

"But orang-orang ini yang tidak tahu segala tetek bengek dan langsung mereka menjudge satu-satu itu, otak paling bemalas tahu eh, orang Maluku bilang otak tarabetendang."

Walaupun Pita sudah menjadi warga negara Amerika, sering berkomunikasi dan lebih lancar berbahasa Inggris daripada Bahasa Indonesia terlihat dari sikapnya yang tetap mempertahankan dialek dari daerahnya. Argumentasi yang diucapkan Pita tidak lepas dari dialek Maluku bahkan beberapa bahasa daerah sering diucapkan oleh Pita berulang kali.

Berdasarkan vlog yang telah dianalisa, peneliti melihat selain memiliki argumentasi yang cukup kuat, Pita ternyata memiliki suatu hal yang menarik dari segi keahlian dalam menyampaikan sebuah pesan. Aristoteles (Rakhmat, 255:2005) mengatakan bahwa persuasi dapat tercapai apabila karakteristik personal seorang pembicara yang ketika ia menyampaikan pembicaraannya membuat orang lain akan mempercayainya. Begitupun sebaliknya dengan Pita yang memproduksi vlog berisi rutinitas dan membagikannya ke media sosial
Youtube membuat orang berasumsi bahwa Pita merupakan seorang Youtuber yang menyediakan konten vlog berisi rutinitas sehari-hari.

Berdasarkan pernyataan tersebut, peneliti menggunakan konsep psikologi komunikator sebagai indikator yang mengukur kualitas Pita sebagai sumber pesan yaitu melalui kredibilitas, atraksi, dan kekuasaan.

a. Kredibilitas

Melalui faktor kredibilitas, peneliti hanya memfokuskan pada dimensi ethos dimana kredibilitas seorang komunikator tidak hanya berdasarkan pada keahlian (expertise) menyampaikan pesan, namun juga dapat dipercaya (trustworthiness).

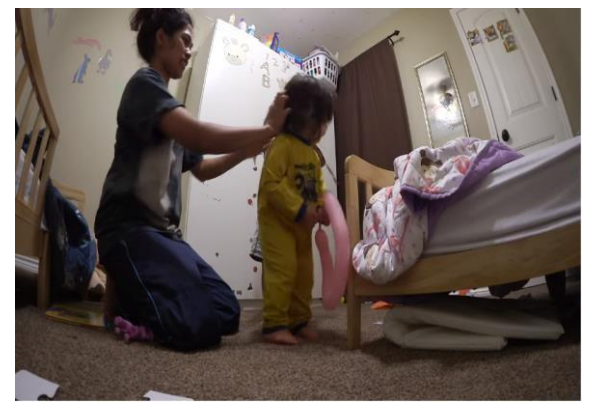

Gambar 2 Pita merawat anak

Bukan suatu hal yang mudah untuk melakukan pekerjaan sebagai seorang Youtuber dengan keadaan memiliki dua orang anak yang masih kecil, tentunya waktu untuk melakukan pekerjaan sebagai Youtuber akan terhambat, namun tidak sebagai Pita. Pita tetap mengurus anaknya terlebih dahulu bahkan sambil melakukan pekerjaannya sebagai Youtuber. Sedangkan kepercayaan yang berusaha dibangun oleh Pita melalui vlognya, sangat terlihat bahwa rutinitas yang ditunjukkan Pita adalah murni kegiatan harian yang dijalankannya sebagai istri sekaligus ibu dari kedua anaknya, 
sehingga membuat tayangan vlognya tidak terlihat sebagai tayangan settingan. Berdasarkan analisis peneliti terhadap vlog Pita, peneliti melihat Pita sangat cukup memiliki Ethos.

b. Attactiveness (Atraksi)

Atraksi atau attactiveness merupakan daya tarik persuasif yang bersumber dari kondisi fisik seorang komunikator. Ketika komunikator tersebut memiliki daya tarik, maka komunikasi akan dirasa lebih efektif (Rakhmat, 2005:264). Daya tarik yang ada pada Pita di vlognya yaitu :

a) Pita sebagai sosok sederhana karena didalam vlog Pita terlihat tidak malu untuk menunjukkan dirinya yang berantakan. Walaupun baju yang digunakan adalah baju yang terkesan romol atau biasabiasa saja, merekam dirinya dengan kondisi baru bangun tidur, tanpa make up, bahkan terus terang mengatakan bahwa dia tidak mandi selama beberapa hari, namun begitu Pita terlihat tetap percaya diri.

b) Pita tidak meninggalkan kearifan karena berdasarkan analisis penulis melalui Pita's Life vlog. Pita sangat sering menggunakan terminologi Maluku tempatnya berasal seperti: "Ngana ni paling kaya bemalas tau eh" "Ini orang gila sekali eh"

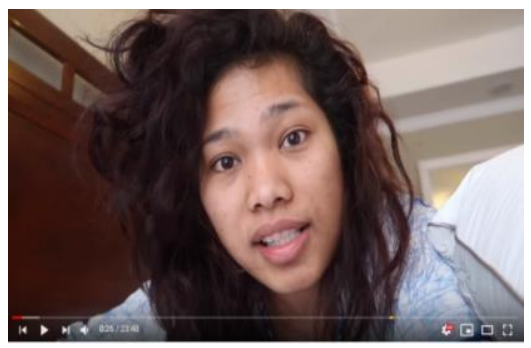

Gambar 3 Pita tanpa make up

c. Mobilitas sosial Vertikal
Pita berasal dari pulau Bacan, yang merupakan sebuah pulau kecil dan sangat terpencil di Maluku, dan berkuliah di Manado. Kemudian menikah dengan seorang tentara Amerika Serikat, dan mulai terkenal saat bergabung dengan Youtube, namun Pita tidak pernah sombong dan masih menunjukkan dirinya yang sederhana dan apa adanya. Hal tersebut terlihat pada saat Pita adalah ketika Pita pulang berlibur ke kampung halamannya pada bulan Agustus tahun 2018. Pita terlihat layaknya orang biasa, mulai dari masak menggunakan kayu, pergi ke pasar dengan jalan kaki, makan makanan seadanya, kemana-kemana naik motor dan angkutan umum, berbeda dengan kehidupannya selama di Amerika, yang masak menggunakan kompor gas, kemana-mana menggunakan mobil, belanja di Walmart, makan di McDonald, KFC, Starbucks, tetapi Pita tidak terlihat gengsi untuk menunjukan kehidupan keluarganya.

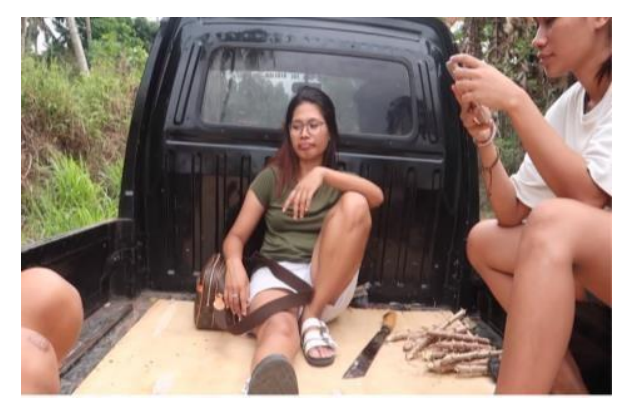

Gambar 4 Pita sedang bersama keluarga di kampungnya

\section{Kerja keras}

Daya tarik selanjutnya yang peneliti pelajari melalui tayangan Pita's Life vlog adalah sisi wanita orang Timur yang ada dalam diri Pita. Pita bekerja layaknya pembantu di rumah, mulai dari mengurus anak, mengurus rumah, halaman belakang, cuci pakaian, masakurus anjing-anjing, cuci mobil, 
dan membersihkan kotoran anjing, semua dilakukannya sendiri tanpa menyewa jasa baby sitter atau pembantu.

Daya tarik lainnya adalah walaupun Pita bekerja seperti pembantu di rumah, Pita ternyata pintar berdandan.

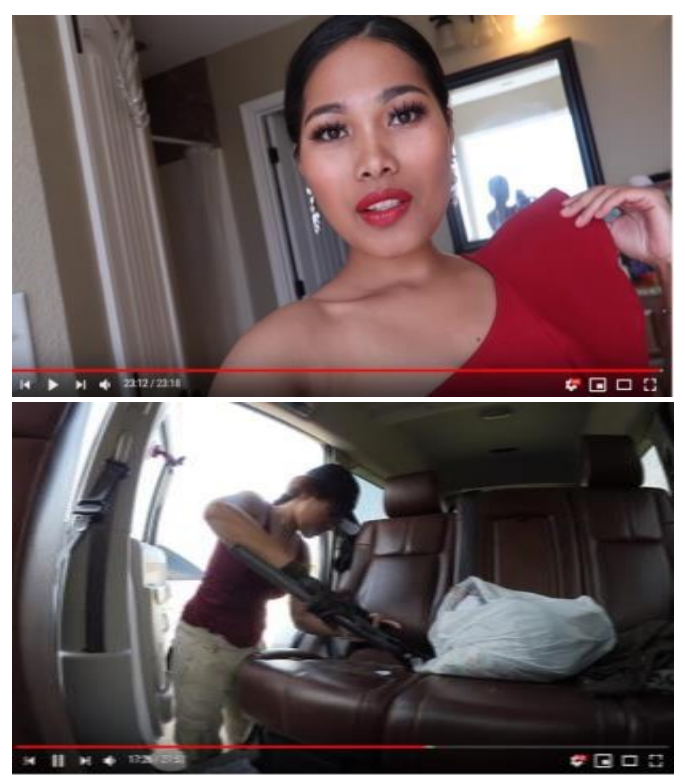

Gambar 5 Kerja Keras Pita

\section{Kekuasaan}

Berdasarkan hasil analisis pada tayangan vlog Pita, peneliti melihat bahwa Pita memiliki power yang cukup kuat. Pita mampu menjadi ibu sekaligus ayah buat kedua anaknya ketika suaminya bertugas berbulan-bulan. Pita harus mengurus anak- anaknya mulai dari memandikan, memasak, membaca dongeng sebelum tidur, bermain bersama kedua anaknya di taman, bahkan mengantar dan menjemput anaknya dari Daycare (tempat belajar anak-anak) sendirian.



Gambar 6 Merawat Anak

Kekuatan Pita lainnya adalah Pita sama sekali tidak bergantung pada suaminya, karena Pita bekerja mencari uang sendiri yaitu sebagai Youtuber.

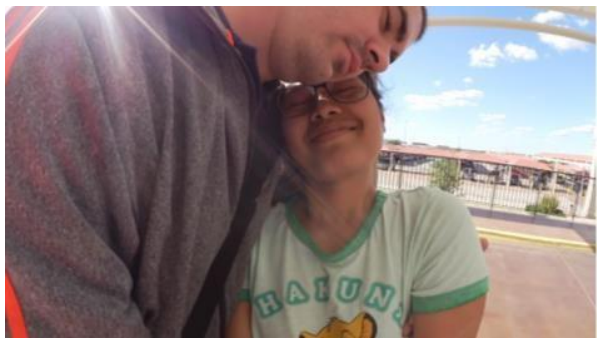

Gambar 7 Pita dan Suami

Hal tersebut terlihat pada salah satu vlog yang menayangkan perpisahan Pita dengan suaminya yang mau bertugas, Pita tidak menangis ataupun terlihat cengeng atau cemas Pita melepas kepergian suaminya dengan senyuman, karena Pita merasa bahwa Pita memiliki uang sendiri sehingga walaupun tanpa suami, Pita terlihat mampu untuk menghidupi dirinya dan kedua anak- anaknya.

\section{PEMBAHASAN}

Berdasarkan hasil analisis terhadap Pita's Life vlog, peneliti menemukan bahwa baik jalur sentral maupun jalur periferal merupakan proses yang tujuannya adalah untuk menyukseskan proses komunikasi yang terjadi melalui media Youtube. Berdasarkan hasil analisis elaborasi pesan secara kognitif melalui jalur sentral yang dilihat melalui keterlibatan Pita bersama orang-orang sekitar yaitu 
suami dan anak- anaknya, terlihat bahwa argumentasi- argumentasi yang disampaikan oleh Pita sebagai sumber pesan di dalam vlog, memiliki makna masing-masing. Adanya keterlibatan Pita bersama suami dan kedua anakanaknya, membuat Pita lebih sering mengucapkan argumentasi tentang keluarganya. Melalui argumentasi yang disampaikan Pita, sangat terlihat bahwa Pita adalah sosok wanita yang peduli, serta menyayangi keluarga. Walaupun terkadang ada beberapa kalimat yang sebenarnya kurang pantas untuk diucapkan, tetapi setelah peneliti mempelajari sosok yang bersangkutan didalamnya yaitu Pita bahwa seseorang tidak akan selalu memiliki sisi yang selalu positif. Di dalam diri seseorang antara baik dan buruk selalu berdampingan. Namun, dari analisis yang peneliti temukan dari jumlah tipetipe argumentasi bahwa Pita merupakan sosok yang memiliki sisi positif lebih banyak dibanding dari sisi negatif, hal tersebut dikarenakan kalimat yang digunakan Pita dalam berkomunikasi di vlog adalah kalimat yang positif.

melalui jalur periferal peneliti
menemukan bahwa sebenarnya tayangan Pita terlihat biasa- biasa saja, namun dengan adanya karakter Pita yang sederhana dan tampil apa adanya menjadikan vlog Pita sebagai tayangan yang menarik dan di sukai disukai oleh banyak orang. Peneliti juga melihat bahwa Pita adalah sosok yang unik, karena dia sangat terbuka dengan kehidupannya. Menjadi sosok yang terkenal di Youtube tidak membuat Pita malu untuk menunjukkan keadaan sederhana dan situasi yang dialaminya. Walaupun sebenarnya konten yang ditayangkan adalah konten seputar rutinitasnya setiap hari, tetapi dengan berlandaskan karakter yang sederhana dan apa adanya menjadi daya tarik tersendiri dalam vlognya sehingga membuat Pita's Life vlog disukai oleh kalangan penonton

Dengan melibatkan Model Elaboration Likelihood dalam penelitian ini, peneliti menemukan bahwa baik kualitas argumentasi dan kredibilitas sumber pesan sama-sama memiliki kesan dalam pembentukan personal branding. Berdasarkan argumentasi dan kredibilitas personal yang ditunjukan oleh Pita melalui Youtube, hal tersebut bukan sematamata hanya untuk sekedar mencari penghasilan dan mengejar popularitas sebagai Youtuber Indonesia, namun Pita disini juga ingin berusaha membentuk pandangan penonton terhadap dirinya sama halnya dengan yang dia inginkan. Dalam hal ini, peneliti melihat bahwa Pita cukup mampu mempersuasi orang lain sebagai sosok yang positif, namun hal tersebut juga tergantung bagaimana orang tersebut memproses pesan yang disampaikan.

\section{PENUTUP}

\section{Kesimpulan dan Saran}

Berdasarkan hasil analisis penelitian yang dilakukan pada vlog Pita's Life di Youtube channel pada bab sebelumnya dapat disimpulkan Baik jalur sentral maupun melalui jalur periferal pada Model Elaboration Likelihood, merupakan proses yang 
memiliki tujuan yang sama yaitu untuk menyukseskan penerimaan informasi yang diterima melalui Pita's Life vlog.

Proses elaborasi dikatakan melalui jalur sentral apabila melibatkan pemikiran secara kognitif terhadap argumentasi yang disampaikan oleh komunikator. Banyaknya strong argument pada hasil penyajian data membuktikan bahwa argumentasi yang disampaikan Pita di dalam vlog berisi hal-hal yang positif, dimana argumentasi tersebut sekaligus mewakili personal dirinya.

Proses elaborasi dikatakan melalui jalur periferal apabila penerima pesan tidak melibatkan elaborasi pesan secara kognitif melainkan hanya melihat kepada siapa yang berbicara atau sumber pesan tersebut. Dengan memiliki ethos, atraksi (daya tarik), dan kekuasaan didalam vlog, Pita mampu menarik perhatian kalangan masyarakat untuk menonton vlognya dan memberikan respon positif. Pembentukan personal branding tidak hanya dilihat melalui kalimat yang diucapkan tetapi juga bagaimana komunikator tersebut mencerminkan dirinya dengan baik melalui media yang digunakan. Oleh sebab itu, adanya kualitas argumentasi dan kredibilitas sumber yang dimiliki oleh Pita membuktikan bahwa pembentukan personal branding di Youtube channel dapat dianalisis dengan menggunakan Model Elaboration Likelihood.

\section{DAFTAR PUSTAKA}

Biagi, Shirley. 2010. Media/Impact Pengantar Media Massa: Media/Impact An Introduction to Mass Media. Jakarta: Salemba Humanika.

Boarnet, Marlon G. \& Crane, Randall. 2001. Transport By Design: The Influence ofUrban Form on Travel. Oxford University Press, United Kingdom. Diakses pada 6 Januari 2017. http://en.bookfi. org/book/1168559

Griffin. 2010. A First Look at Communication theory. 8th edition. Boston: McGraw Hill.

Kertajaya, Hermawan. 2000. Marketing Plus 2000, Siasat Memenangkan. Persaingan Global. Jakarta : PT. Gramedia Pustaka Utama

Krippendorff. 2005. Content Analysis (An Introduction to Its Methodology). California : Sage Publications.

Mcnally, David. Dan Speak, D. Karl.2004. Be Your Own Brand (Resep Jitu Meraih Personal Branding yang Unggul). Jakarta : PT Gramedia Pustaka Utama

Mc Quail, Denis. 2011. Teori Komunikasi Massa, Jakarta: Salemba Humanika.

Morissan. 2015. Teori Komunikasi Individu Hingga Massa. Jakarta: Kencana.

Nurudin, 2012. Media Sosial Baru dan

Munculnya Revolusi Proses

Komunikasi. Yogyakarta:

Buku Litera

Nasrullah, Rulli. 2017. Media Sosial 
JURNAL NOMOSLECA

Volume 5 Nomor 1, April 2019

Perspektif Komunikasi,

Budaya, dan Sosio Teknologi.

Bandung: Simbiosa Rekatama

Media.

Rakhmat, Jalaluddin. 2005. Psikologi

Komunikasi. Bandung: PT

Remaja Rosdakarya.

Rusdianto, Ujang. 2014. Cyber CSR; A
Guide to CSR

Communications on Cyber Media, Graha Ilmu : Yogyakarta

Sugiyono. 2015. Metode Penelitian Kuantitatif,Kualitatif, dan R\&D. Bandung: Alfabeta 